\title{
Primary Tuberculosis of Tonsil in a Diabetic Patient-A Case Report
}

\author{
Nagula Parusharam¹, Kamreddy Ashok Reddy', Lokesh Rao Magar², Jadi Lingaiah ${ }^{3}$ \\ ${ }^{1}$ Department of E.N.T., Kakatiya Medical College, MGM Hospital, Warangal, India \\ ${ }^{2}$ Department of Pathology, Kakatiya Medical College, MGM Hospital, Warangal, India \\ ${ }^{3}$ Department of ENT \& HNS, Chalmeda Anand Rao Institute of Medical Sciences, Karimnagar, India \\ Email: parashuramnagula@gmail.com, drjadi ms@yahoo.com
}

Received 22 March 2015; accepted 12 April 2015; published 17 April 2015

Copyright (C) 2015 by authors and Scientific Research Publishing Inc.

This work is licensed under the Creative Commons Attribution International License (CC BY).

http://creativecommons.org/licenses/by/4.0/

(c) (i) Open Access

\begin{abstract}
Though Tuberculosis is one of the most common causes of ill health and death worldwide, people with diabetes have 2 - 3 times higher risk of tuberculosis when compared with people without diabetes. Though tuberculosis can affect any part of the body, oral and oropharyngeal tuberculosis is rare, but reported. And it's association with diabetes mellitus because of the decreased host mechanism, is still rare, but reported. A 50-year-old female diabetic who was on insulin therapy came to OPD of MGM hospital, Kakatiya Medical College, Warangal with complaints of severe pain in throat for the last 6 months. On examination, right tonsil was enlarged with granular surface. Left tonsil and rest of the oropharynx were normal. Examination of chest was normal and there was no evidence of pulmonary tuberculosis. Punch biopsy revealed tuberculosis of tonsil. Isolated cases of primary tuberculosis of tonsil without evidence of pulmonary tuberculosis are rare. Presence of diabetes mellitus makes patients 2 - 3 times more vulnerable for tubercular infection.
\end{abstract}

\section{Keywords}

Tonsil, Primary Tuberculosis, Diabetes Mellitus

\section{Introduction}

Pulmonary tuberculosis (TB) is a common disease in India and also worldwide, but it is very rarely seen in oral cavity and orpharynx as primary tuberculosis. Isolated tuberculosis of tonsil without pulmonary involvement is a rare entity [1]. Nowadays, diabetes mellitus (DM) is also common in most parts of the world. Tuberculosis is 2 3 times more common in diabetes mellitus [2]. Non healing ulcer commonly points towards malignancy. In a 
non healing ulcer, if malignancy is not likely, then the most common differential diagnosis will be chronic granulomatous condition, of which TB is more common. After taking the consent from the patient to publish, we report such a case of primary tuberculosis of tonsil in a diabetic patient, mimicking ulcerated growth of tonsil.

\section{Mini Literature Review}

Both diabetes and tuberculosis are well recognized for their huge global burdens. Nearly one third of the world's population is infected with $M$. tuberculosis and about $10 \%$ is at risk of developing an active disease in their lifetime. At the same time, prevalence of diabetes is increasing alongside other noncommunicable diseases [3]. There are numerous studies from different regions of the world supporting this.

A country with one of the largest number of TB cases is India. In this highly endemic country, over $25 \%$ of TB patients were found to have diabetes and $24 \%$ pre-diabetes [4]. Altogether almost $50 \%$ of TB patients had some form of hyperglycemia. The risk factors for diabetes were similar to those in the general population such as increasing age, body mass index (BMI) category $\left(18.5-22.9 \mathrm{~kg} / \mathrm{m}^{2}\right)$, positive family history and sedentary occupation. Of interest, among TB patients with diabetes, almost $60 \%$ had been diagnosed with diabetes before. It is most likely that long-term diabetes has a negative effect on the immune response and may enhance TB morbidity. In another study from India, the number of TB patients needed to screen (NNS) to find one newly diagnosed diabetic case was 4 [5]. It was confirmed that nearly half of TB patients had diabetes, which was independently associated with male sex and age above 50 years. In another retrospective study from India, diabetes was found as the most frequent risk factor for pulmonary tuberculosis, far more common $(30.9 \%)$ than classic risk factors for TB such as smoking (16.9\%), alcoholism (12.6\%), human immunodeficiency virus (HIV) (10.6\%), malignancy $(5.8 \%)$ as well as history of contact with TB (3.4\%) and chronic corticosteroid therapy $(2.9 \%)$ [6]. The strength of DM as a risk factor for TB appears to be equivalent to that of HIV infection. In a case-control study conducted in California, Pablos-Méndez et al. found that among Hispanics aged 25 - 54 the estimated risk due to DM was $25.2 \%$ whereas that due to HIV infection was $25.5 \%$ [7]. Higher risk for TB among diabetic patients was also confirmed in a Mexican study (prevalence of DM among TB patients: $39 \%$ in Texas and $36 \%$ in Mexico) [8]. Namely, diabetes contributed to TB five times more often than HIV infection ( $25 \%$ vs. $5 \%)$. It could be stated that the risk of TB due to DM seems to be smaller at the individual level compared with that of HIV infection (113-170-fold) [9]. However, it can also be said that at the population level the sheer numbers of diabetic patients are likely to have an equal or even greater effect. What is more, established risk factors for TB such as alcohol and drug abuse as well as HIV infection were found less frequently in the diabetic group [8] [10].

\section{Case Report}

A 50-year-old female of Asian race who was on treatment for Diabetes Mellitus came to OPD of Mahatma Gandhi Memorial Hospital, Kakatiya Medical College, Warangal, India with pain in throat and pain on swallowing. She also complained of ulcer in the throat for the past 6 months. There was no history of fever or cough. On examination right tonsil was enlarged (grade 3) and surface was granular in appearance (Figure 1(a) and Figure 1(b)). There were no acute signs of inflammation. Anterior and posterior pillars were normal. Left tonsil was normal. Posterior pharyngeal wall was normal. Indirect laryngoscopy was normal. There was no evidence of cervical lymphadenopathy. No history of weight loss. And family history was nil particular. And there was no history of milk intake as regular diet. On auscultation Lungs were clear.

\section{Investigations}

Routine investigations showed Hb\%-12 gm\%, TLC-10 500/mm ${ }^{3}$, N-69\%, L-25\%, E-04\%, M-02\%, B-00\%. RBC count-4 million/ $\mathrm{mm}^{3}$, ESR-90 mm 1st Hour, RBS-130 mg/dl. Complete Urine Examination-Normal, Blood Urea $27 \mathrm{mg} \%$, S. Creatine $1 \mathrm{mg} \%$, Mantoux Test-17 mm Positive after 48 Hrs. HIV 1 and 2-Negative and HBsAgNegative, Chest X-Ray-Normal (Figure 2). Punch biopsy done under local anaesthesia and sent for histopathological examination. Histopathological examination reported as multiple sections studied shows structure of lymphoid tissue with marked number of lymphocytic infiltration, few granulomas noticed. Each granuloma consists of central caseous necrosis surrounded by epithelioid layer, lymphocytic layer, few Langhan's giant cells surrounded by a layer of fibroblasts, features suggestive of chronic inflammatory pathology i.e. chronic tuberculous 


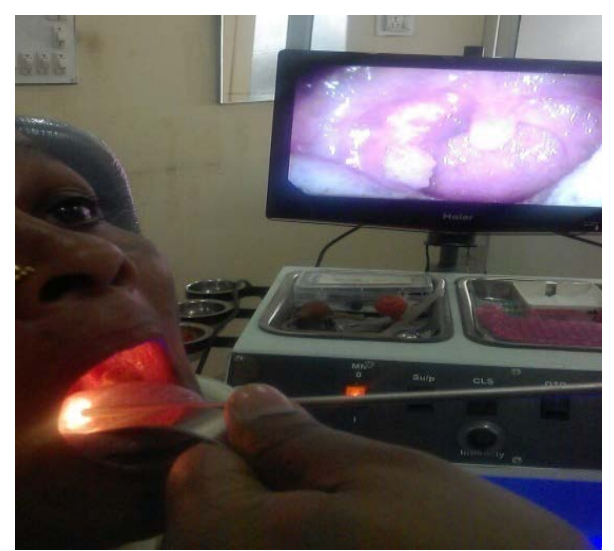

(a)

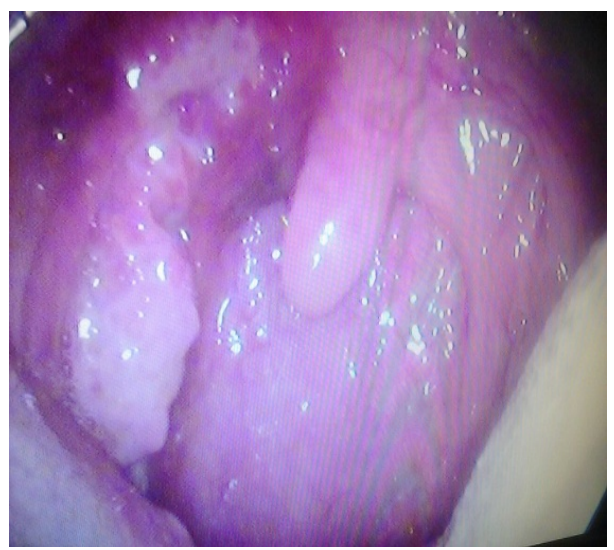

(b)

Figure 1. Endoscopic view of enlarged right tonsil with pale granular appearance.

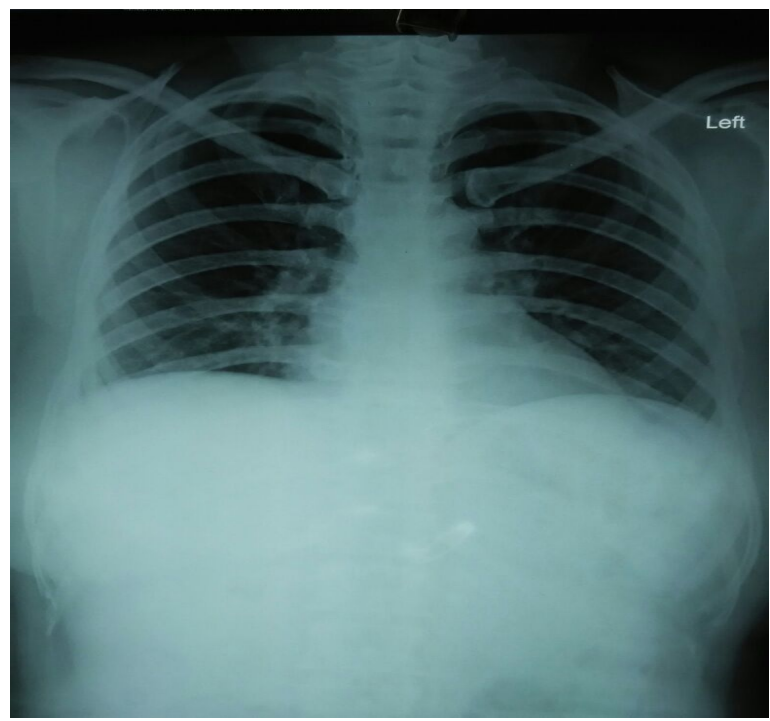

Figure 2. Normal X-ray chest.

tonsillitis (Figure 3 and Figure 4).

Patient was started on Anti Tuberculous Treatment (ATT) with 4 drug regimen consisting of ETHAMBUTOL$500 \mathrm{mg}+$ ISONIAZIDE-300 mg + PYRAZINAMIDE-750 mg + RIFAMPICICIN-450 mg for 2 months and ISONIAZIDE and RIFAMPICIN for 4 months. Patient responded well to the antituberculous treatment with tonsillar surface becoming normal without any granular appearance and symptoms disappeared completely after six months (Figure 5).

\section{Discussion}

Tuberculosis in humans is caused by mycobacterium tuberculosis and mycobacterium bovis. Though Tuberculosis can affect any part or organ of the body, pulmonary tuberculosis is most common which is about $75 \%$ of the cases, extra pulmonary tuberculosis being remaining $25 \%$ of overall morbidity of tuberculosis [11]. Among extra pulmonary tuberculosis, most commonly involved are lymph nodes. Other forms of extra pulmonary tuberculosis are like CNS, Genito urinary, abdominal, pericarditis, etc. Tuberculosis of oral cavity and tonsil is rare and usually secondary to pulmonary tuberculosis [12]. Primary tuberculosis affecting palatine tonsil is still extremely rare [13]. People with weak immune system as a result of chronic diseases such as diabetes mellitus and HIV are at high risk. People with diabetes mellitus have 2 - 3 times higher risk of tuberculosis when compared 


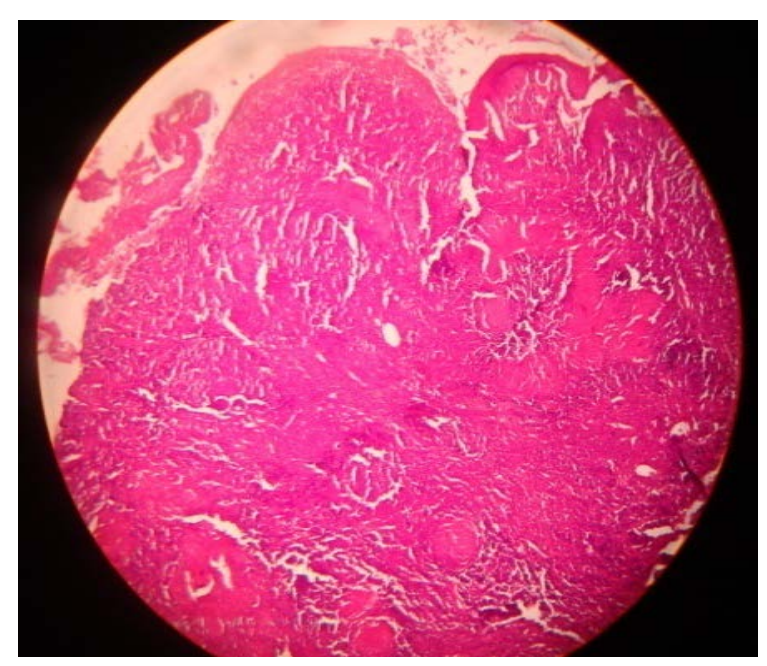

Figure 3. Microscopic appearance $(4 \times)$.

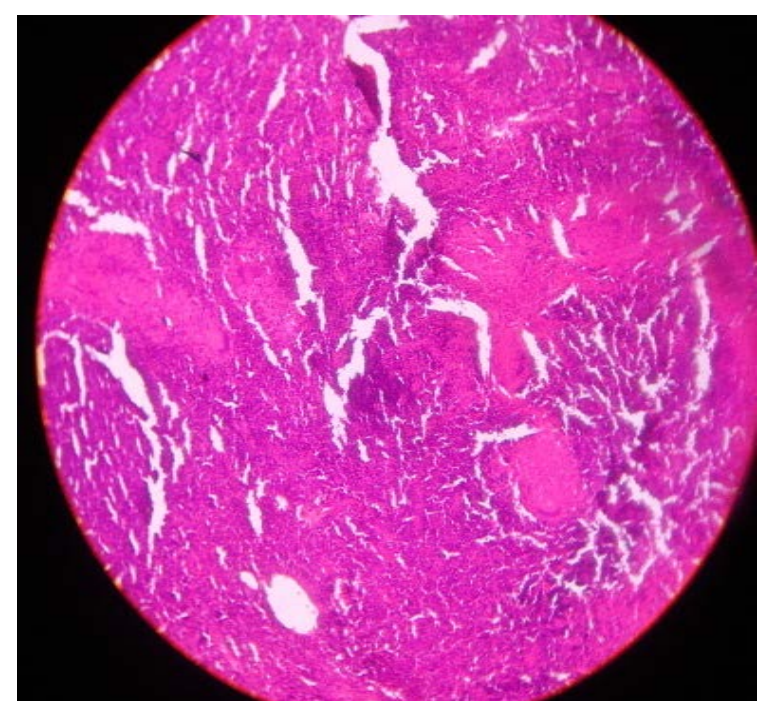

Figure 4. Microscopic appearance $(20 \times)$.

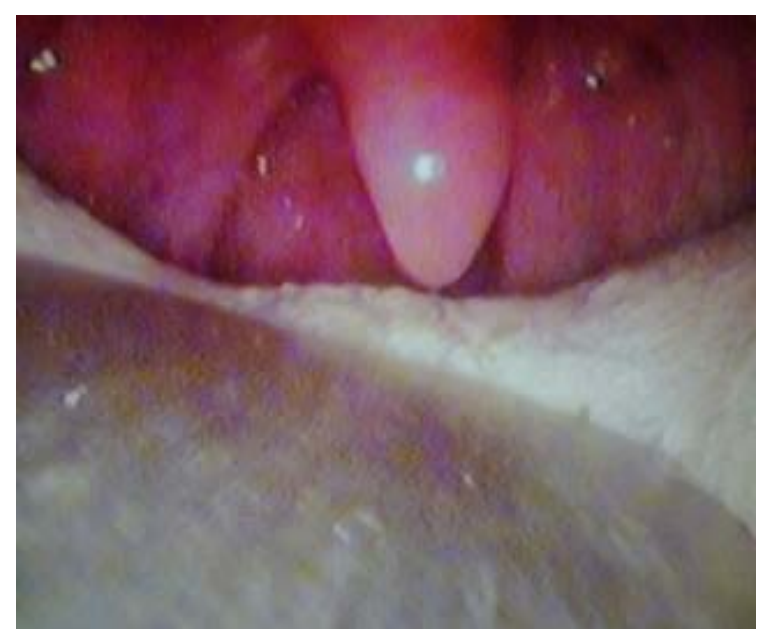

Figure 5. After 6 months of treatment right tonsil became normal. No granular surface. 
to people without diabetes mellitus. About $10 \%$ of tuberculosis cases globally are linked to diabetes mellitus [2].

Oral and oropharyngeal tuberculosis is uncommon, may be primary or secondary. Incidence of tonsillar tuberculosis is less than 5\% [14]. Tonsil may be primarily infected by contamination with material containing tubercle bacilli. These patients commonly present with sore throat. With availability of pasteurized milk, the incidence of TB has decreased as concluded by Miller in 1963 [15].

Tuberculosis of the tonsil is a rare disease because of the salivary act of antiseptic cleaning-mechanism [16] and epithelial covering of oropharyngeal mucosa has inhibitory effect on tubercule bacilli [17]. It has been documented that such infection may be acquired by inhalation and disease may be harboured in waldeyers ring [18]. Although tuberculosis tonsil is rare, tonsillar granulomata are commonly seen in patients with decreased immunity due to diabetes mellitus, HIV or chronic alcoholism. This patient was diabetic initially on oral antidiabetic drugs but was not under control. Then she was started Insulin to bring her diabetes under control. Predisposing factors for primary oral and oropharyngeal tuberculosis are poor dental hygiene, periodontitis, leukoplakia. But this present case does not have these as predisposing factors.

Malignancy, syphilis, lymhpoma, taumatic ulcer, haematological disorders and other granulomatous conditions are differential diagnosis [19]. Arbols indicators [14] may help to think about this entity.

Arbols indicators are:

a) Pain on swallowing;

b) Obliteration of crypts;

c) Tonsillar enlargement without exudates;

d) Granular enlargement of tonsil.

The diagnosis is based on histopathological findings of tubercular Langhan's giant cells in a tonsillar tissue.

This case highlights the importance of being aware of association TB and DM the possibility of TB ulcer should be kept in mind in case of a non healing, non malignant looking ulcer in a diabetic patient.

\section{Conclusions}

It is concluded that tonsillar tuberculosis still exists and may be a diagnostic challenge to otolaryngologists. Tuberculosis of Tonsil is suspected in a patient if the tonsil is enlarged, with rough and granular surface with or without cervical lymph node enlargement, who is complaining of pain in throat and pain on swallowing. And more so if patient is also a diabetic.

In this case, only right tonsil is enlarged, the left tonsil being normal and there is no evidence of cervical lymph node enlargement, proper investigations and biopsy can confirm the diagnosis. Early detection and treatment are essential for cure. Decreased host immune mechanism like diabetes mellitus can predispose to tubercular infection and tonsillar granulomata with or without cervical lymphnode enlargement. Isolated unilateral tubercular infection of the tonsil without cervical lymphnode in a diabetic patient is rare, which encouraged us to report this case.

\section{References}

[1] Kant, S., Verma, S.K. and Sanjay (2008) Isolated Tonsil Tuberculosis. Lung India, 25, 163-164. http://dx.doi.org/10.4103/0970-2113.45284

[2] WHO (2011) www.who.int/tb/publications/2011

[3] Skowroński, M., Zozulińska-Ziółkiewicz, D. and Barinow-Wojewódzki, A. (2014) Tuberculosis and Diabetes Mellitus-An Underappreciated Association. Archives of Medical Science, 10, 1019-1027. http://dx.doi.org/10.5114/aoms.2014.46220

[4] Viswanathan, V., Kumpatla, S., Aravindalochanan, V., et al. (2012) Prevalence of Diabetes and Pre-Diabetes and Associated Risk Factors among Tuberculosis Patients in India. PLoS ONE, 7, e41367. http://dx.doi.org/10.1371/journal.pone.0041367

[5] Balakrishnan, S., Vijayan, S., Nair, S., et al. (2012) High Diabetes Prevalence among Tuberculosis Cases in Kerala, India. PLoS ONE, 7, e46502. http://dx.doi.org/10.1371/journal.pone.0046502

[6] Gupta, S., Shenoy, V., Mukhopadhyay, C., Bairy, I. and Muralidharan, S. (2011) Role of Risk Factors and SocioEconomic Status in Pulmonary Tuberculosis: A Search for the Root Cause in Patients in a Tertiary Care Hospital, South India. Tropical Medicine \& International Health, 16, 74-78. http://dx.doi.org/10.1111/j.1365-3156.2010.02676.x

[7] Pablos-Méndez, A., Blustein, J. and Knirsch, C. (1997) The Role of Diabetes Mellitus in the Higher Prevalence of Tu- 
berculosis among Hispanics. American Journal of Public Health, 87, 574-579.

[8] Restrepo, B., Camerlin, A., Rahbar, M., et al. (2011) Cross-Sectional Assessment Reveals High Diabetes Prevalence among Newly-Diagnosed Tuberculosis Cases. Bulletin of the World Health Organization, 89, 352-359. http://dx.doi.org/10.2471/BLT.10.085738

[9] Corbett, E., Watt, C., Walker, N., et al. (2003) The Growing Burden of Tuberculosis: Global Trends and Interactions with the HIV Epidemic. JAMA Internal Medicine, 169, 1009-1021. http://dx.doi.org/10.1001/archinte.163.9.1009

[10] Restrepo, B., Fisher-Hoch, S., Smith, B., Jeon, S., Rahbar, M. and McCormick, J. (2008) Short Report: Mycobacterial Clearance from Sputum Is Delayed during the First Phase of Treatment in Patients with Diabetes. The American Journal of Tropical Medicine and Hygiene, 79, 541-544.

[11] Farer, L.S., Lowell, A.M. and Meader, M.P. (1992) Extra Pulmonary Tuberculosis in USA. American Journal of Epidemiology, 109, 205-217.

[12] Lathan, S.R. (1971) Tuberculosis of the Palate. Journal of the American Medical Association, $216,521$. http://dx.doi.org/10.1001/jama.1971.03180290095030

[13] Cleary, K. and Batsakis, J.G. (1955) Mycobacterial Disease of the Head and Neck: Current Perspective. Annals of Otology: Rhinology and Laryngology, 104, 830-833. http://dx.doi.org/10.1177/000348949510401015

[14] Balasubramanian, T. (2012) Tonsillar Tuberculosis: A Literature Review. Otolaryngology Online.

[15] Miller, F.J., Seal, W. and Taylor, M.D. (1963) Tuberculosis in Children. J \& A Churchill Ltd., London.

[16] Verma, A., Mann, S.B.S. and Randotra, B. (1989) Primary Tuberculosis of the Tongue. Ear, Nose and Throat Journal, 68, 719-720.

[17] Rauch, D.M. and Freidman, E. (1978) Systemic Tuberculosis Initially Seen as an Oral Ulceration: Report of a Case. Journal of Oral Surgery, 36, 384-389.

[18] Selimoğlu, E., Sütbeyaz, Y., Çiftçioğlu, M.A., Parlak, M., Esrefoğlu, M. and Öztürk, A. (1995) Primary tonsillar tuberculosis: a case report. The Journal of Laryngology \& Otology, 109, 880-882. http://dx.doi.org/10.1017/S0022215100131573

[19] Adiego, M.I., Millán, J., Royo, J., Dománguez, L., Castellote, M.A., Alfonso, J.I. and Vallés, H. (1994) Unusual Association of Secondary Tonsillar and Cerebral Tuberculosis. Journal of Laryngology and Orology, 108, 348-349. http://dx.doi.org/10.1017/S0022215100126738 